\title{
BMJ Open Experiences of elderly patients regarding participation in their hospital discharge: a qualitative metasummary
}

\author{
Ingvild Lilleheie, ${ }^{1}$ Jonas Debesay, ${ }^{2}$ Asta Bye, ${ }^{2,3}$ Astrid Bergland ${ }^{1}$
}

To cite: Lilleheie I, Debesay J, Bye $\mathrm{A}$, et al. Experiences of elderly patients regarding participation in their hospital discharge: a qualitative metasummary. BMJ Open 2019;9:e025789. doi:10.1136/ bmjopen-2018-025789

- Prepublication history and additional material for this paper are available online. To view these files, please visit the journal online (http://dx.doi. org/10.1136/bmjopen-2018025789).

Received 08 August 2018 Revised 13 August 2019 Accepted 06 September 2019

Check for updates

(c) Author(s) (or their employer(s)) 2019. Re-use permitted under CC BY-NC. No commercial re-use. See rights and permissions. Published by BMJ.

${ }^{1}$ Department of Physiotherapy, Oslo Metropolitan University, Oslo, Norway

${ }^{2}$ Department of Nursing and Health Promotion, Oslo Metropolitan University, Oslo, Norway

${ }^{3}$ Regional Advisory Unit for Palliative Care, Department of Oncology, Oslo University Hospital, Oslo, Norway

Correspondence to

Ingvild Lilleheie;

ingvild.lilleheie@0slomet.no

\begin{abstract}
Background Ageing patients are discharged from the hospital 'quicker and sicker' than before, and hospital discharge is a critical step in patient care. Older patients form a particularly vulnerable group due to multimorbidity and frailty. Patient participation in healthcare is influenced by government policy and an important part of quality improvement of care. There is need for greater insights into the complexity of patient participation for older patients in discharge processes based on aggregated knowledge.

Objective The aim of this study was to review reported evidence concerning the experiences of older patients aged 65 years and above regarding their participation in the hospital discharge process.

Methods We conducted a qualitative metasummary. Systematic searches of Medline, Embase, Cinahl, PsycINF0 and SocINDEX were conducted. Data from 18 studies were included, based on specific selection criteria. All studies

\section{Strengths and limitations of this study}

This study used the application of a rigorous and systematic metasummary technique.

- This is the first metasummary of perspectives of patients regarding their own hospital-discharge process.

- The Joanna Briggs Institute Qualitative Assessment and Review Instrument (JBI-QARI) Critical Appraisal Checklist for Qualitative Research was employed to assess the quality of original research articles.

- The metasummary method limited us to findings that were considered important or significant by researchers, and thus it may have missed findings that were considered minor in the original studies but that could have emerged as important in several studies.

- The subjects represent a relatively limited sample of the global population.
\end{abstract} explored older patients' experience of participation during the discharge process in hospital, but varied when it came to type of discharge and diagnosis. The data were categorised into themes by using thematic analysis. Results Our analysis indicated that participation in the discharge process varied among elderly patients. Five themes were identified: (1) complexity of the patients state of health, (2) management and hospital routines, (3) the norm and preference of returning home, (4) challenges of mutual communication and asymmetric relationships and (5) the significance of networks.

Conclusions Collaboration between different levels in the health systems and user-friendly information between staff, patient and families are crucial. The complexity of patient participation for this patient group should be recognised to enhance user involvement during discharge from hospital. Interventions or follow-up studies of how healthcare professionals can improve their communication skills and address the tension between client-centred goals and organisational priorities are requested. Organisational structure may need to be restructured to ensure the participation of elderly patients.

\section{INTRODUCTION}

Hospital discharge is a critical step in patient care. In particular, older hospitalised patients form a particularly vulnerable group due to multimorbidity and frailty. ${ }^{1}$ For this group of patients, successful discharge from hospital depends greatly on good planning to provide patient-centred care during their safe journey through the healthcare system to reduce readmissions to hospitals. ${ }^{2}$ This process includes effective collaboration and communication between patients, their carers/next of kin and health professionals when moving across care settings. ${ }^{3}{ }^{4}$ However, in the last decade, a recurrent global theme has emerged where ageing patients are being discharged from hospital 'quicker and sicker' ${ }^{5-7}$ As the average length of stay decreases, the healthcare provider has less time to coordinate services across settings and to prepare the patients for their situation at home.

The term 'patient participation' can be defined as 'a patient's rights and opportunities to influence and engage in the decisionmaking about his care through a dialogue attuned to his preferences, potential and a combination of his experiential and the professional's expert knowledge'. ${ }^{9}$ We know that successful patient participation is associated with satisfaction with healthcare services, ${ }^{10}$ a lower number of readmissions, ${ }^{11}$ 
better treatment outcomes ${ }^{12}$ and shorter institutional stays. $^{13}$

Research suggests that the implementation of user participation in healthcare services is far from complete. ${ }^{14-16}$ The importance of patient participation in their discharge from hospital and the limited amount of research into the experiences of older patients suggests that there is a need for greater insights into the complexity of patient participation based on aggregated knowledge. Several studies have addressed these topics separately, but to our knowledge, this is the first study systematically to aggregate knowledge regarding the experiences of older patients about their participation in hospital discharge. Thus, this study's objective is to review reported evidence concerning the experiences of older patients aged 65 years and above regarding their participation in the hospital-discharge process. We explored how the rights and opportunities of patients to influence the decisions made about their own care through dialogue were attuned to their preferences, potential abilities and a combination of their experience and the expert knowledge of professionals. This study, based on a qualitative design, presents important information about how health professionals can contribute to the identification of important topics to facilitate tailored good discharge practices.

\section{METHODS}

\section{Design}

We conducted a qualitative metasummary based on the approaches and methods described by Sandelowski and Barroso $^{17}$ to combine the findings of qualitative studies. A qualitative metasummary is an approach for synthesising research where qualitative findings are collected from topical or thematic surveys of data by reviewing the relevant literature. The method involves treating research reports as indices of the studies conducted and the research findings in these reports as indices of the experiences of the persons who participated in those studies. ${ }^{18}$ In our study, the findings were integrated and summarised. The frequency of each finding was determined and a particular finding with a higher frequency had greater validity. ${ }^{17} 19$

\section{Search method}

Systematic searches of Medline, Embase, Cinahl, PsycINFO and SocINDEX were conducted. These databases were considered most appropriate for our literature searches because they cover articles within the fields of health and social sciences. A librarian conducted a comprehensive literature search in September 2017, with a follow-up search in March 2018. The search was conducted using the terms 'patient discharge', 'discharge', 'hospital discharge' and 'discharge planning' linked with 'geriatric patients', 'aged', 'older', 'elder', 'elderly' and 'frail' linked with 'patient participation', 'patient-centered care', 'decision making', 'patient satisfaction', 'patient preferences' and 'personal autonomy'. To ensure that



Figure 1 Identification and selection of studies. Source: Moher, Liberati, Tetzlaff, Altman and the PRISMA Group (2009). For more information, visit www.prisma-statement. org.

qualitative research was included, we linked the terms above with the terms 'qualitative research', 'hermeneutics', 'grounded theory', 'observation', 'anthropology/ cultural', 'focus groups', 'interview', 'narration', 'ethnographic research', 'personal narratives' and 'perception'. Studies were limited to qualitative research written in English and published no later than March 2018. The search strategy used is described in online additional file 1 . Figure 1 shows a flowchart illustrating the process employed for selecting the articles.

\section{Selection criteria}

Titles, abstracts or full-text studies were scanned to ensure their adherence to the following inclusion criteria:

- Studies using qualitative methodology.

- Exploring older patients aged 65 years or over.

- Self-reported experiences with relevance to the research topic.

- Experiences of participation in a hospital-discharge process.

- Original research including peer-reviewed articles.

\section{Exclusion criteria}

- Ph.D. theses.

- Not written in the English language.

\section{Characteristics of the primary studies}

Following initial screening, 44 potentially relevant fulltext articles were assessed further to determine their eligibility and 26 articles were excluded, thereby leaving 18 articles that satisfied the inclusion criteria for this qualitative metasummary. Each study was systematically assessed in terms of the research questions addressed, statement of purpose, research method, sample size, characteristics of 
participants, settings and country where the research was conducted. We included studies about the user experiences of older people with multiple chronic health conditions because focusing on single diseases would have been excessively specific and not necessarily generalisable to older people with multiple chronic conditions, and thus exclusions were not made based on the diagnosis or cause of admission. All 18 studies included elderly patients aged 65 years and older. The sample sizes varied from 5 to 60 participants (a total of 262 elderly patients). All of the studies explored the experiences of the patients while participating in the hospital-discharge process. Twelve studies were performed based on semistructured interviews that focused on the discharge process. The selected studies were conducted in Canada, Sweden, Norway, the UK, New Zealand and the USA. The number of published studies increased from 1994 to 2017, with two studies in 1994 and the remainder after 2006 (see table 1).

\section{Study selection}

Two authors independently assessed the references retrieved from the search and any disagreements were resolved subsequently. The studies included were individually appraised using the Joanna Briggs Institute Qualitative Assessment and Review Instrument (JBI-QARI) (see online supplementary appendix). This instrument was used by the authors to assess the quality of original research articles. The aims of this appraisal were to ensure that the reports met the inclusion criteria, as well as to familiarise the authors with the informational content, methodological orientation, style and form of each study. ${ }^{17}$ The checklist contains nine questions that require a yes, no or unclear response. All studies scored a minimum of five yeses and it was agreed by both reviewers that all 18 studies were of sufficient methodological quality to be accepted for the review. No disagreements between reviewers arose (see table 2 ).

\section{Synthesis of findings}

Qualitative metasummary results can serve as the empirical foundations for more interpretive qualitative research synthesis methods. ${ }^{18}$ The articles were reviewed, and patient statements were extracted from each study regarding experiences of participation in hospitaldischarge processes. The original research findings from the selected studies were synthesised using thematic analysis, ${ }^{20-22}$ a method for identifying, analysing and reporting patterns in qualitative data. Initially, all the authors read the transcribed material in an open way, searching for meaning and patterns. To ensure consistency of data analysis, we adopted the six-phase approach to thematic analysis described by Braun and Clarke. ${ }^{20}$ This approach has been widely used and accepted as robust across a wide range of disciplines, including human health research. ${ }^{23}$ To maximise trustworthiness and limit threats to validity, we employed the criterion for 'trustworthiness' outlined by Lincoln and Guba. ${ }^{24}$ We satisfied the criterion of credibility through open-ended questioning, prolonged engagement with the data and by providing a detailed description of the methods. We fulfilled the criterion of transferability by presenting detailed and in-depth descriptive data and by quoting the participants. To satisfy the criterion of dependability, reiterative reading of the transcripts all of the authors was performed to transform the ideas generated into a set of codes to identify the interesting features of the data. These initial codes were then categorised into potential themes. The themes were discussed and reviewed by all authors to reflect on their relevance to the research questions. ${ }^{25}$ We obtained the saturation of content from the ninth article, that is, the additional papers did not provide substantial knowledge. The themes were then refined to ensure that each was meaningful and clear but distinct from other themes. ${ }^{26}$

\section{Patient and public involvement}

Patients and public were not involved in this study.

\section{RESULTS}

The analysis identified the following five overarching themes that influence the experiences and opportunities of elderly patients regarding participation in the discharge process: (1) complexity of the elderly patient's state of health, (2) management and hospital routines, (3) the norm and preferences regarding returning home, (4) challenges of communication and asymmetric relationships and (5) the significance of a care network. Table 3 shows the frequency of the themes in the different studies.

\section{Theme 1-Complexity of the elderly patient's state of health}

Elderly patients generally comprise a vulnerable population likely to be affected by chronic illness and cognitive impairments, ${ }^{34}$ which make patient participation challenging. Studies have shown how dynamic interactions between the elderly patient's mental state, health condition, physical function and environmental factors might influence their ability and capacity to participate in the discharge process. ${ }^{27-32}$

Several patients stated that they often struggled to understand and remember the information provided to them on the day of discharge: ${ }^{30-33}$ 'I'm just going home, am I not? I thought ... So I did not really follow what they were talking about', 'I got information, but I do not remember much' ${ }^{32}$ Their mental state influenced the experience of participation, but there were doubts even in the cases where the elderly patients felt capable of making their own decisions during the discharge process: 'I thought it went pretty well ... as long as I'm in control; I can decide how I want it.' The ability to participate in the discharge process depended on the patient retaining some control of the situation. ${ }^{28}$

Some patients experienced problems when making decisions about their own care needs because of their reduced state of health: ${ }^{27-30} 33$ ' (I was) exhausted, exhausted, so exhausted and ... weak and ... tired ... So the discharge planning conference was not of any value to $m e^{30}{ }^{30}$ The patients 


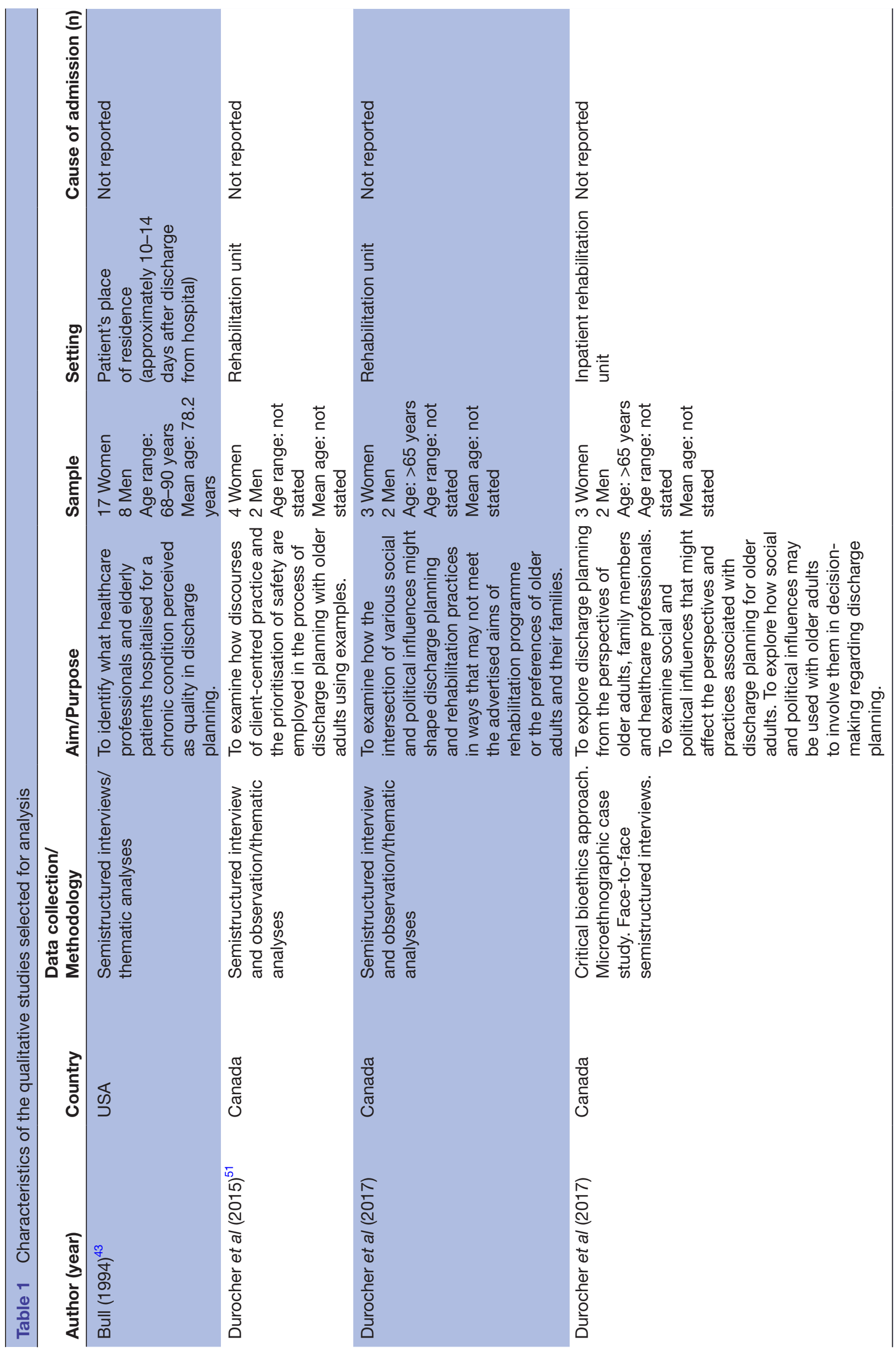




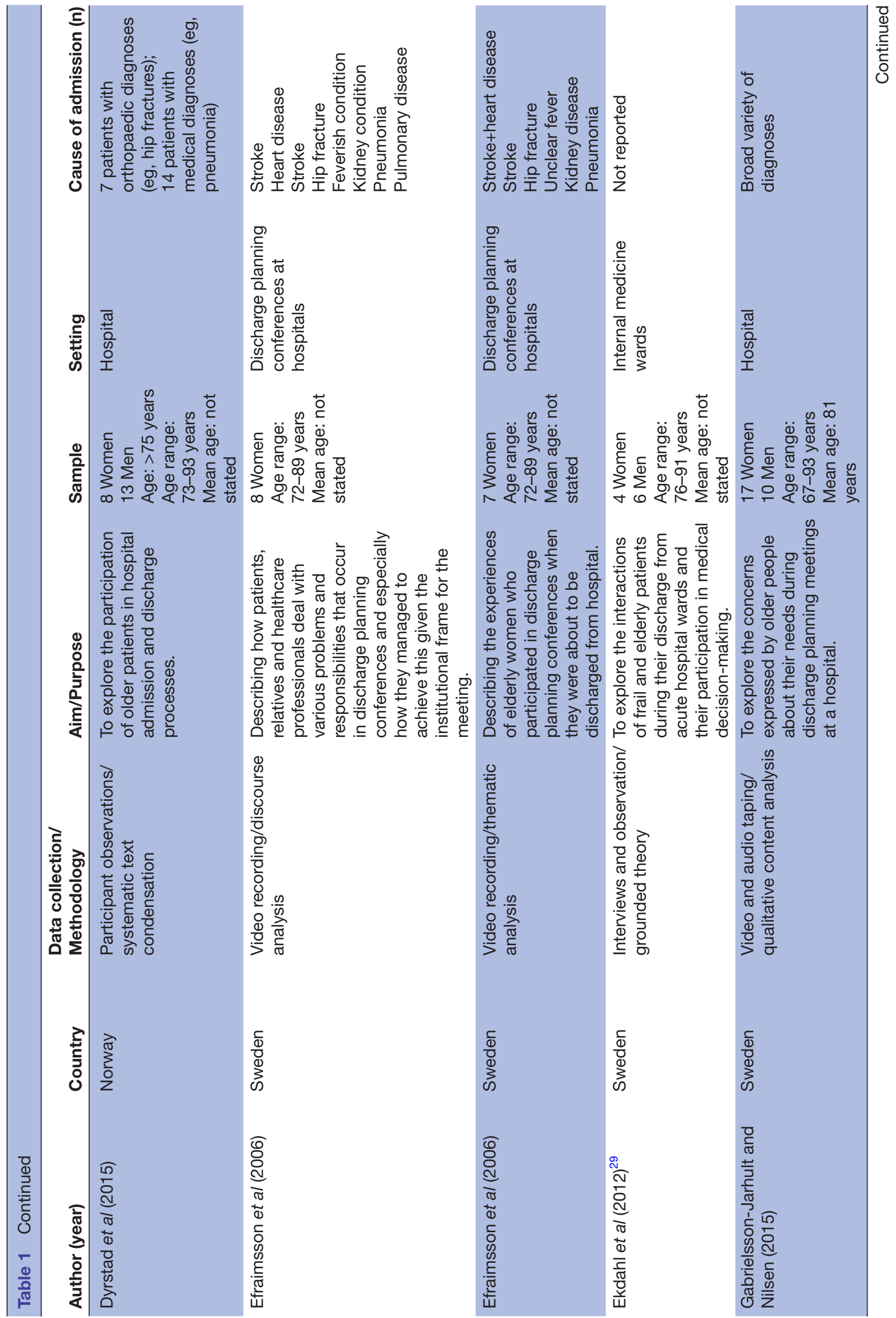




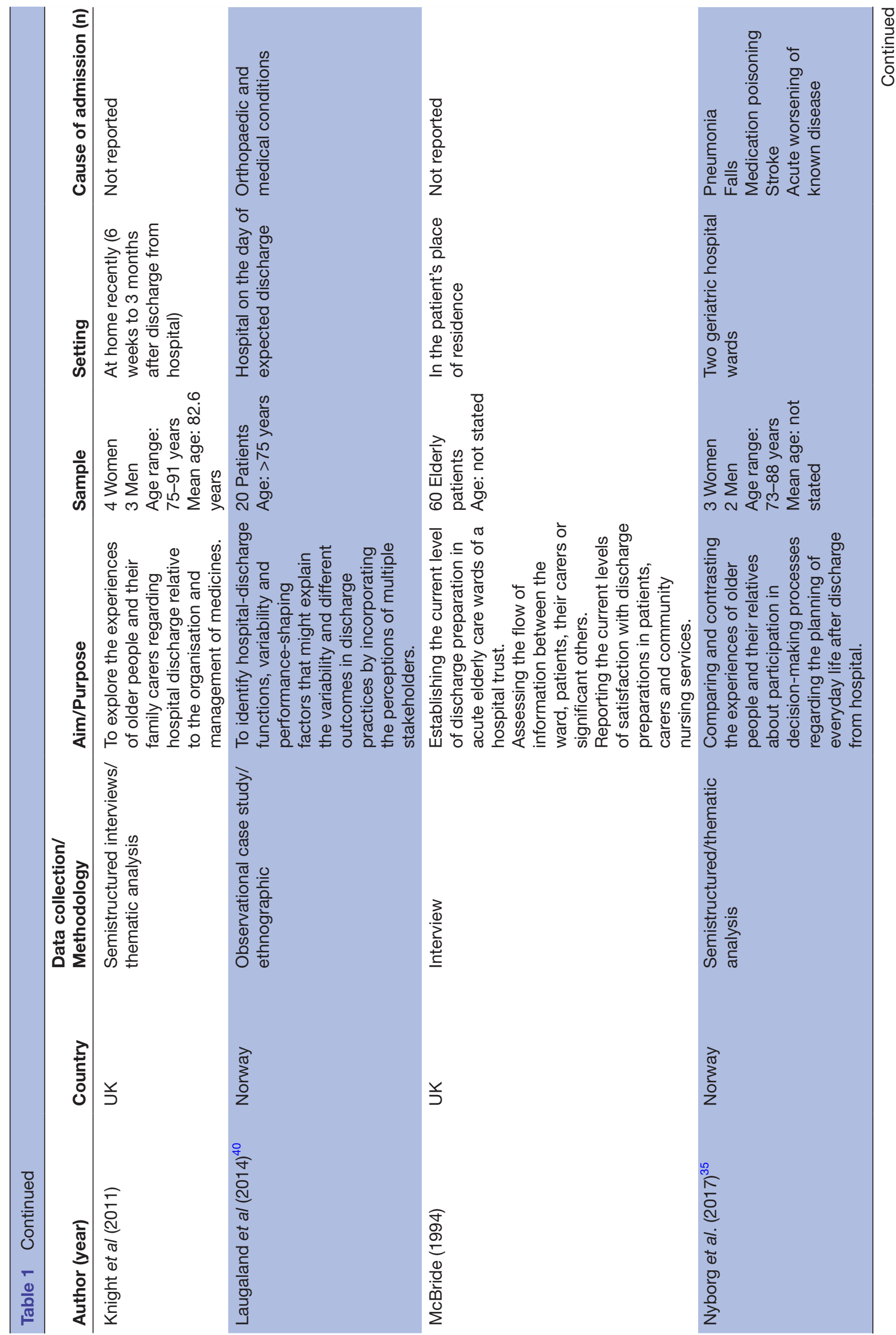









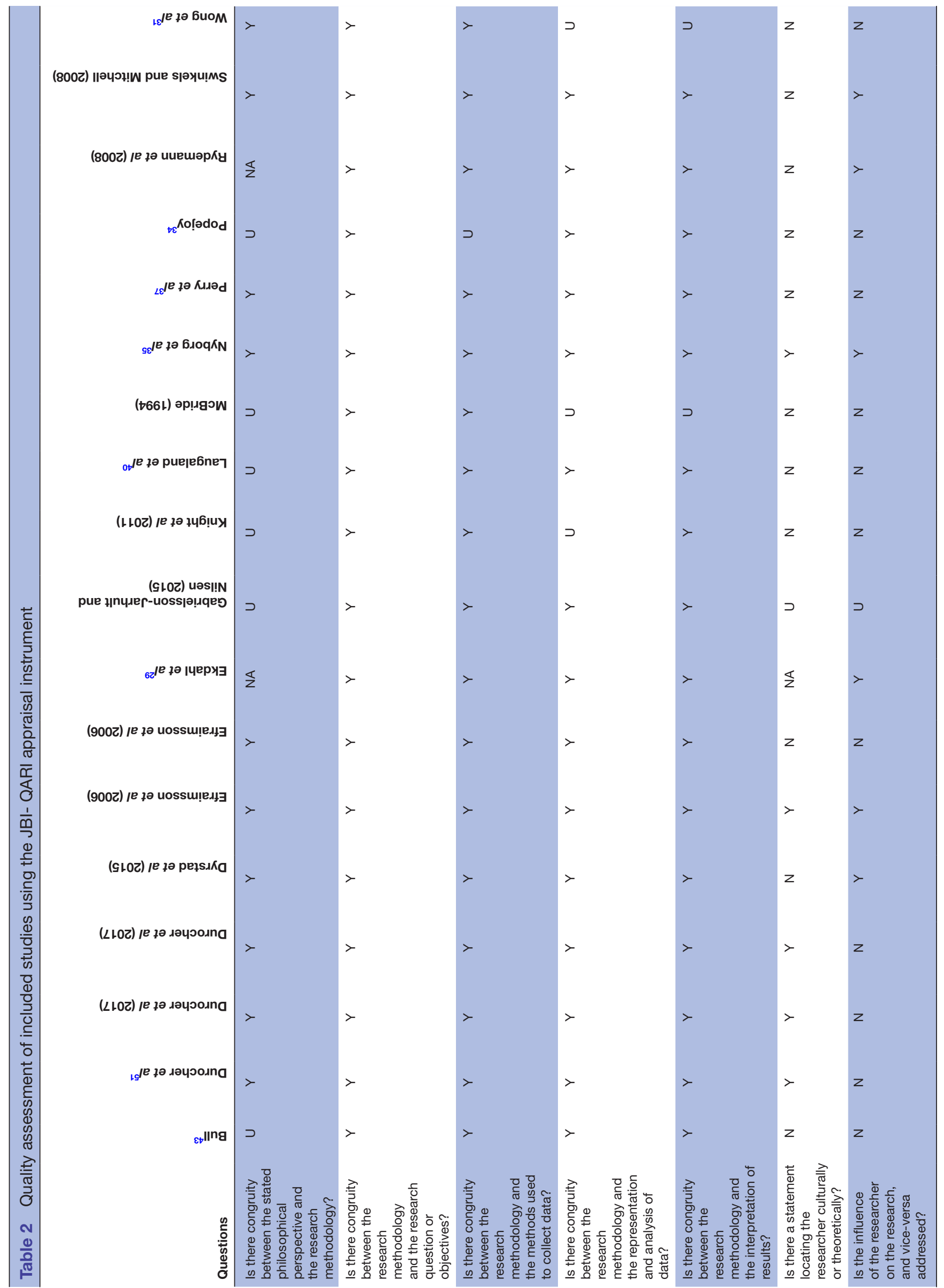









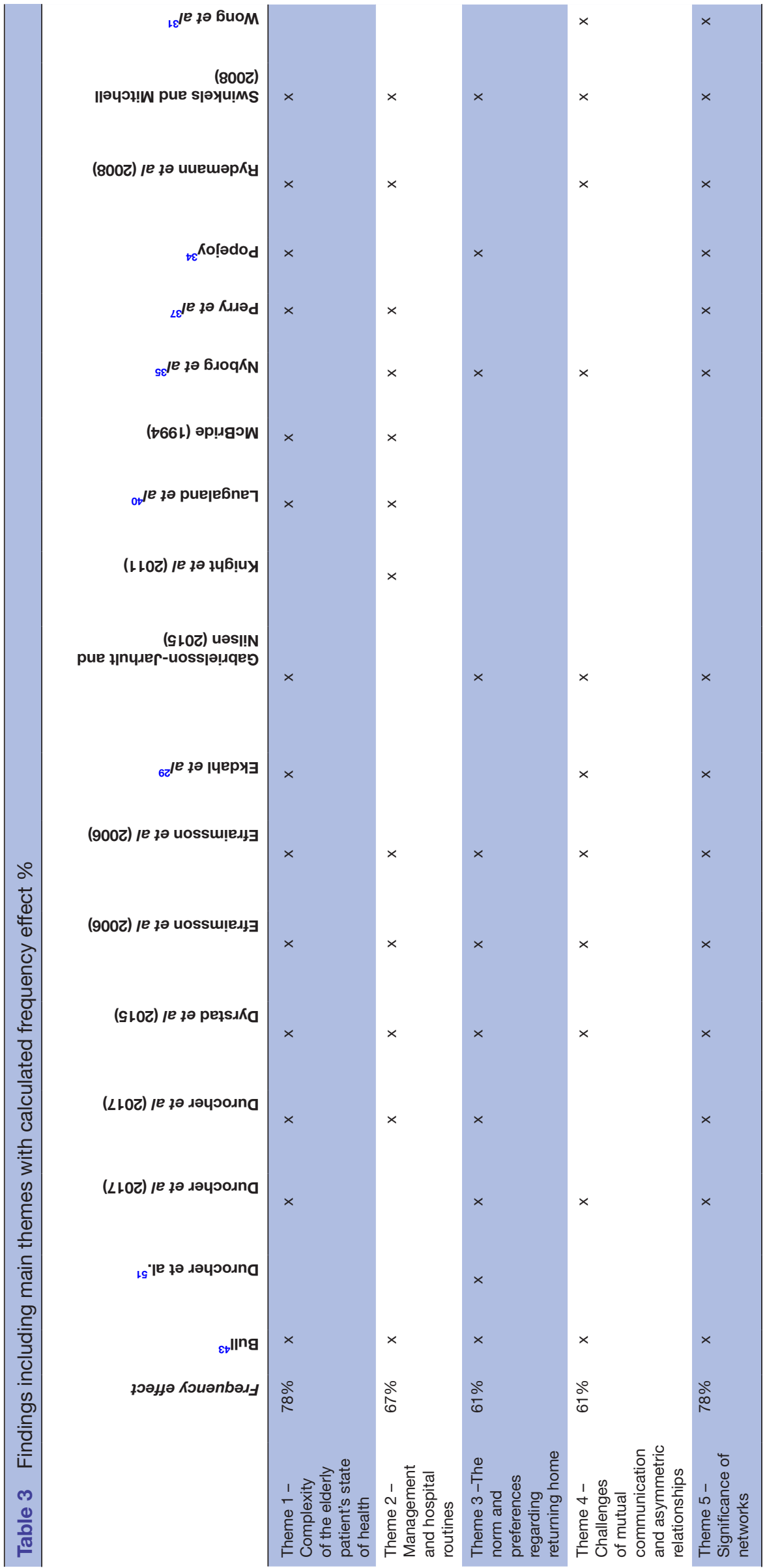


described themselves as 'slow and helpless 30 and not able to 'see their way out of it. ${ }^{27}$ Others described the challenges they experienced as follows: 'I feel as if the future is uncertain and I don't know how life will end up. Am I going to be better or remain disabled and, in that case, how severely? I don't know if I will ever be able to take care of myself, if I can go back home or where I will stay'."

Reduction in mobility was a source of anxiety and frustration for many of the patients: ${ }^{27-29} 34$ ' Well, I would like to go home, but I am so weak and trembly. I am not walking very good ${ }^{34}$ and 'I can tell you immediately that I can't do the cleaning and washing ... because I can't do it sitting in the wheelchair and my hands are occupied when walking with those crutches' ${ }^{28}$ Injury and disease affected them greatly and their prerequisites for daily life changed. They lost their strength and their ability to manage personal care, prepare meals, walk and move freely. Therefore, they wanted to feel better before returning home: 'I think it's totally wrong to send me home. I've been here for two days and now I'm going home again. But I'm no better than I was when I came here. ${ }^{29}$

\section{Theme 2-Management and hospital routines}

Our analysis showed that older patients felt that participation in the discharge process could not occur without considering the surrounding services and the underlying health policy. ${ }^{27} 3536$ The patients said they were aware of the fact that discharge planning starts shortly after admission. ${ }^{37}$ The patients stated that the discharge process appeared to be influenced by the need to get the patient through the system efficiently and quickly, to keep costs down and to clear hospital beds ${ }^{32} 37$ : 'I was so disappointed when I got discharged. I told them I couldn't manage at home and needed to stay a few more days. But the doctor told me there was no place at all for me on the ward or in hospital. ${ }^{39}$ However, when the final notification of the discharge came, it was often unexpected: ${ }^{3740-42}$ 'You never quite know what time you are going to be allowed to go home.

Studies showed that organisational conditions imposed pressure on the work situations of healthcare professionals, thereby affecting how the patients described their experiences of participation. ${ }^{27} 3743$ Durocher et $a l^{33}$ found that despite the intentions of health professionals to engage with older patients in the discharge process, the process itself followed a standard format that did not encourage contributions from older adults. Thus, the limitations in the organisational structures of hospitals affected the ability of older patients to participate in the discharge process. ${ }^{33} 363839$ Moreover, when an elderly patient perceived that the healthcare professionals were hurried, or 'treating (us) as a machine', they were less inclined to provide information about their own situation. ${ }^{43}$

Differences in primary healthcare and special health services also influenced the experiences of elderly patients and their ability to participate in the discharge process. ${ }^{27}$ In some studies, the patients expressed concerns about collaboration between the different levels in the health system involved in their discharge. They spoke about how 'the routines started in the hospital should continue in an uninterrupted manner' after discharge. ${ }^{43}$ They also talked about how those responsible for their discharge came from outside the hospital: 'Nobody tells me [(about leaving hospital)]. I asked them [nurses] but they don't even know themselves. ${ }^{27}$

\section{Theme 3-The norm and preferences regarding returning home}

In most countries, public policy for decades has aimed to ensure that people should live in their own homes for as long as possible. ${ }^{44-46}$ Studies have also shown that people want to live in their own homes when they are older and weakened. $^{46-49}$

Eleven of the studies emphasised that older people wanted to get back home. ${ }^{27} 283032-3638435051$ This was confirmed by the descriptions of how elderly patients were eager to return home and they stated that their primary desire was to return to their familiar surroundings:"28323436384351 'Yes, that is what I would like. One is longing to be back home again', 'I will not leave my home. My home is my castle', 'I want to be in my own place,, 27 and 'I want to go home ${ }^{36}$ The patients in these studies valued the comfort and familiarity associated with staying at home, and the opportunity they had to participate in habitual activities 272830363851 : 'I want to be free, free and everything. I want to be in my own place where I was making cakes and things, ${ }^{27}$ Others described 'the freedom to invite guests, play bridge, and easily visit their families ${ }^{51}$ Despite these findings, several studies detected ambivalence regarding how the elderly patients would manage at home 3035 : 'I wonder if I will ever be able to go home again, ${ }^{30}$ This ambivalence affected the experiences of elderly patients when participating in the discharge process. 'Yes, it's a lot to think about when lying awake at night. Will I manage to get back home?'. If an elderly patient would not consider a discharge destination other than home, this affected how they chose to participate: 'You do what you have to do to stay home.'.

\section{Theme 4-Challenges of mutual communication and asymmetrical relationships}

Adequate information, discussion of uncertainties, an empathic response and knowledge exchange are essential parts of patient participation. ${ }^{2728} 30323536$ The following quotes illustrate the desire of the elderly patients for sufficient and necessary information to participate in the discharge process: 'I miss information. What has happened and what is going to happen?', 'It was hard ... When other people are making decisions that concern yourself 30 and 'I did not really follow what they were talking about. ${ }^{36}$

Five studies found that good lines of communication between staff, patients and their families were crucial for the experience of participation. ${ }^{3336394043}$ It was shown that 'communication' maintained the dignity and autonomy of patients, as well as contributing to understanding the importance of participation among patients. ${ }^{27-30} 3233$ However, a collaboration between patients and health professionals could be challenging. Thus, Durocher et $a l^{33}$ 
described how 'the elderly were expected to absorb the information provided by the healthcare professionals and carry out their instructions' and the healthcare professionals answered the patient's questions only at the end of the meeting if there was sufficient time. Several studies found that the elderly did not understand the meaning of conversations with healthcare professionals. ${ }^{303343}$ For example, one of the participants in a study only understood Polish and no one was aware of this until the end of the meeting regarding her discharge. This indicates a lack of effort to engage patients in their own discharge process. ${ }^{33}$

In several studies, the terminology used by the professionals was seen as a barrier to participation: $:^{30} 323343$ ' In the health area, they use a lot of terminology; to the ordinary person, it's Greek. ${ }^{43}$ The lack of distinct information and understandable language affected the contributions made by patients to the process and their experience of participation. ${ }^{30} 323343$ The inability to understand the information content was also a challenge for elderly patients, which was resolved by the capacity of their surrounding network in many cases: 'It is very good having my daughter present when information is given; it makes me feel safe. When my daughter has received the same information, she can repeat it to $m e^{32}{ }^{32}$

One study ${ }^{36}$ described how the participants were expected to comply with the formal regulations specified by the health professionals in conversations, the judgments of professional carers about the care needs of women and the bureaucratic rules of the institutions. A 'civilised' conversational tone was preferred in conversations regarding the discharge process, but the environment was not conducive to sharing feelings and personal information. The participants were also expected to act as if the discharge process was democratic and the decision was the result of a mutual agreement to everyone's satisfaction. ${ }^{36}$ These complicating factors negatively influenced the experiences of the patients regarding their participation in the discharge process.

Several studies focused on the importance of clientcentred practice, ${ }^{30} 32333643$ but the elderly patients often described this relationship between the health professional and the patient as asymmetrical: ${ }^{27} 293032333643$ 'We just have to obey what they say, ${ }^{30}$ This asymmetrical relationship tended to reinforce the power of the professionals and increase the powerlessness experienced by people with impairments. ${ }^{27}{ }^{36}$ Some studies described situations where the patients experienced a sense of powerlessness and resignation after interacting with the health personnel involved in the decision-making process, ${ }^{29} 3236$ as follows:

Patient: 'I don't think you can influence decisions, and that it's just as well because you don't know. I don't understand the care that much. So, it is enough just to hope they take the right decision.'

Interviewer: 'Do you think so?'

Patient: 'Yes. I can't influence them.' . ${ }^{29}$

As a consequence, the patients felt that they were being excluded from the decisions made regarding their own discharge. ${ }^{27} 2930$ Bull $^{43}$ described how elderly patients who were dissatisfied did not report asking questions, ${ }^{43}$ but instead they avoided making comments and accepted the suggestions of the health personnel without questions or complaints: ${ }^{31} 323639$ 'They know everything; I have been here several times and they know what is best. One cannot interfere in the doctors' job, they find the truth. ${ }^{32}$ In these cases, the patients left it to the 'experts' to make the choice instead of participating in their own discharge process. ${ }^{27} 32$

\section{Theme 5-Significance of networks}

Relatives are given various roles related to the acquisition of information and participating in dialogues. ${ }^{14}$ Several of the studies reported that the patients used families and networks to ensure their participation in the discharge process. $^{28} 30323335-373943$ They used their networks to overcome communication barriers, to transfer information and to improve the quality of the discharge process. ${ }^{30} 32353943$ One of the patients described her daughter's role in the discharge process as follows: 'It means a lot because she is the one who is listening; she listens and finds out ... She is a wonderful help to me in all situations; $;{ }^{30}$ and another one: 'I'll leave things to my daughter to sort out. She's far more capable than I am, so I'll leave everything to her really. ${ }^{27}$

The participants in these studies reported that family and friends assisted them following their discharge, ${ }^{27} 2831$ 35-38 43 such as the following example: ' $I$ am thankful to my wife for letting me stay at home. She does the housework and all. ${ }^{35}$ These contributions were considered when the elderly patients contributed to the discharge process where they described how they influenced their own situation: 'I could not have managed without that ... the family have been wonderful. ${ }^{37}$ Establishing alliances seemed to be a key attribute of patient empowerment and participation in the discharge process, and the following quotes illustrate how patients relied on their network in these situations: 'It feels good having a hand to hold, ${ }^{29}$ and ' $M y$ husband and my son are the world to me. ${ }^{35}$

\section{DISCUSSION}

Our analysis of primary studies indicated that participation in the discharge process varied among elderly patients. Some of them left the responsibility to healthcare professionals whereas others wanted to be more deeply involved. We found that the experience of participation among patients was related to factors such as their personal health status, hospital routines, mutual communication, the asymmetric relationship between health personnel and patients and family networks. However, most of them indicated that they were given few opportunities to participate in shared decision-making regarding their discharge despite the fact that at the healthcare system level, patient participation may potentially reduce healthcare $\operatorname{costs}^{52}$ and medical errors. ${ }^{53}$ The positive costbenefit outcome regarding an improved perception of discharge might be connected with the fact that successful 
patient participation is associated with satisfaction with healthcare services, ${ }^{10}$ a lower number of readmissions ${ }^{11}$ and better treatment outcomes. ${ }^{12}$

The publishing dates for the studies ranged from 1994 to 2017, which is a long period of time. During this period, the hospitalisation length decreased ${ }^{54}$ and awareness of the importance of patient involvement in healthcare increased, ${ }^{95-57}$ but the findings were very similar throughout the entire period. The studies were conducted in seven different countries and there may have been differences in terms of care provision regarding the party responsible for coordinating the discharge process, that is, healthcare providers, social care providers or both, although this was not reflected in the reported findings.

The patient discharge examples indicated that the experience of participation among the elderly patients depended on their cognitive and physical conditions. ${ }^{27-29}{ }^{36}$ An explicitly poorer health condition at the time of discharge made it difficult for the elderly patients to remember information and to follow their conversations with the health personnel, ${ }^{30-32}$ and thus they felt unprepared for leaving the hospital. The primary studies suggested that the details concerning discharge were often provided unexpectedly, ${ }^{3740}$ which led to an unpredictable situation for the elderly patients. ${ }^{27-29} 32373841$ Furthermore, we showed that the patient's family and network had positive effects on patient involvement in hospital discharge, especially when the patient found their relationships with healthcare professionals challenging due to their health status. ${ }^{28303235-3739}$ The participants in the primary studies stated that their relatives compensated for their reduced participation in the process. Thus, these findings highlight the importance of strengthening the collaboration between healthcare professionals and the relatives of older patients.

Our findings showed that many patients described the discharge process as an anxious time because they were never sure when they were going to be allowed to go home, ${ }^{37404143}$ and what to expect from the time after discharge. ${ }^{28} 2936-394243$

According to some of the studies, discharge to their own homes was the preferred option for most patients but few other options were discussed or offered, ${ }^{2732} 344351$ which might reflect the lack of other possible alternatives. Surveys have shown that older people generally want to stay in their own homes for as long as possible ${ }^{470}$ and having people remain in their own homes for as long as possible is favoured by policy makers, health providers and many older people themselves throughout the world. ${ }^{58}$ Indeed, 'The longing for home' might disrupt the participation of patients in the discharge process, so patients will 'do what they have to do' to get back home. ${ }^{34}$

Our findings indicate that communication could be challenging between the patients and health professionals. Instead of being invited to a dialogue attuned to their specific preferences and potential, the communication between the elderly patients and the health personnel led to a feeling of unpreparedness for the patient. Bull et $a l^{59}$ concluded that one of the best predictors of an older patient's satisfaction with discharge planning was the experience of being prepared to manage on their own.

Alliances between patients and staff appeared to have positive effects on the treatment outcomes in rehabilitation, ${ }^{12}$ and patients could experience the benefits associated with involvement when they felt empowered. ${ }^{60-62}$ This emphasises the importance of having a good relationship and maintaining a constructive dialogue between healthcare professionals and patients for ensuring a satisfactory experience of participation in the decision-making process. Better communication between staff, patients, and caregivers could improve the experience of the discharge procedure by patients. ${ }^{63}$ However, our results indicate that elderly patients may find it challenging to be involved and participate actively in the discharge planning process due to difficulties in understanding discussions or not feeling included in conversations. ${ }^{30}$

This review focuses on patients the experiences of participation in the discharge process and indicates the vulnerability of patients in a challenging health service context, which might deprive them of genuine participation. Despite the heterogeneity in the characteristics of the primary study regarding factors as country, sample and cause of admission, the participants' experiences were quite similar. Older adults with multiple chronic conditions receive care that is fragmented and seldom focused on what matters most to the patient. ${ }^{64}$ Many of the patients considered in this survey suffered from multimorbidity, and there was a gap between the prerequisites for participation by patients and the current policy for enhancing patient participation. Patient participation often assumes that all patients have the competence, ability and willingness to participate in important decisions while they are living in health institutions. ${ }^{56}$

The frameworks for participation are often characterised by efficiency requirements, so patient groups with reduced physical and cognitive abilities might have limited opportunities to participate. ${ }^{5865}$ The poor health of older patients and the requirements of hospitals for a rapid discharge process might detrimentally affect the experiences of participation in discharge among these older patients. In addition, some patients with poor health reported that they did not want to participate in their own discharge process due to their limited capacities. Other studies ${ }^{66}{ }^{67}$ also showed that not all patients want to participate in decision-making, and the preferences of older patients regarding their involvement in the decision-making process may differ according to the setting and their current health status. ${ }^{68}$ Some of the participants reported having sufficient trust in the staff. For example, Pearson $e t a l^{69}$ stated they 'leave it to the experts' or their relatives to make the choices. Health professionals also have a tendency to encounter conflict due to ambiguity when there are tensions between the client-centred goals and organisational goals, ${ }^{70}$ which may lead to a dilemma for healthcare professionals. Health personnel are constrained by the goals, 
requirements and limitations imposed by policy and reforms, and they must find a way to resolve the possible incompatibility between client-centred practice and an expedient and efficient discharge process. ${ }^{70}$ Thus, the experience of participation among elderly patients is limited by organisational constraints and the dilemmas that health professionals must address during the course of their work.

\section{Strengths and limitations of this study \\ Strengths}

- The application of a rigorous and systematic metasummary technique: Synthesising qualitative research is considered essential for achieving the goal of evidence-based practice, that is, using the best available evidence as the foundation for practice without methodological prejudice. ${ }^{17}$

- This is the first metasummary of perspectives of elderly patients regarding their own hospital-discharge process.

- This metasummary provides a concise and comprehensive review of recent literature.

- The JBI-QARI Critical Appraisal Checklist for Qualitative Research was employed.

\section{Limitations}

- Only the main healthcare databases were employed, and thus some publications might have been missed.

- The metasummary method limited us to findings that were considered important or significant by researchers, and thus we may have missed findings that were considered minor in the original studies but that could have emerged as important in several studies.

- Since patient statements were extracted from the original studies, this already represented a choice made by researchers in each research team. By repeating these included statements, we are in danger of maintaining the initial selection perspective.

- The articles included focused on the patients perspective and therefore, the perspective of the healthcare system may have been overlooked.

- The subjects represent a relatively limited sample of the global population.

- Some specific patient groups were not present in the sample, such as patients from ethnic minorities, and patients with severe cognitive impairment and aphasia.

- This review was restricted to studies published in English and did not include theses, dissertations or grey literature which may have introduced publication bias.

- No patients or members of the public were involved in the analytical process, which might have been helpful in terms of determining the implications for practice.

- The analysis did not capture any differences in health and social care practices for the population in diverse countries.

\section{Implications for practice}

Shorter hospital stays make patient participation especially important for ageing patients.

To ensure that elderly patients can participate, the strategies employed need to consider the following:

- Healthcare services should be organised in ways that secure person-centred and integrated care for older people.

- Several of the patients in this patient group will probably benefit from 1 or 2 days extra in the hospital.

- Patients must receive relevant information about their treatment.

- The provision of adequate verbal and written communication must be ensured between service providers, professionals, elderly patients and their informal caregivers.

- Healthcare professionals should confirm whether the information provided has been perceived and understood by the patient.

- The perspectives of older patients must be incorporated into decision-making processes.

- Informal caregivers must be involved in discharge planning.

- Health professionals must critically reflect on the tensions between client-centred goals and organisation goals.

- More research is needed regarding barriers to patient participation in the discharge process and possible facilitators.

- Interventions or follow-up studies of how healthcare professionals can improve their communication skills and address the tension between client-centred goals and organisational priorities are requested.

\section{CONCLUSION}

The results of this metasummary contribute to our understanding of the experiences of elderly patients when participating in their own discharge process and they may help to improve the satisfaction of elderly patients with healthcare services in terms of their discharge. For this vulnerable group of patients, successful discharge from hospital depends greatly on good planning and the provision of patient-centred care. Our results highlight the importance of the organisational structure, communication, planning, preparation and involvement based on the complex needs of older patients as well as their caregivers. The complexity of patient participation for this patient group should be recognised to enhance user involvement for elderly patients during their discharge from hospital. To improve the experiences of elderly patients regarding their participation in the discharge process, researchers need to find effective approaches that will facilitate their participation by focusing on the importance of assessment and planning, patient information and education, preparation and the involvement of older patients and their caregivers in the discharge process. Healthcare professionals should improve their communication skills and address the tension between 
client-centred goals and organisational priorities to provide healthcare that is tailored to the most important requirements of elderly patients during the discharge process. The organisational structure may also need to be redefined and restructured to ensure the participation of elderly patients in the discharge process.

\section{Twitter Ingvild Lilleheie @ILilleheie}

Acknowledgements The authors would like to thank the librarian Malene W Gundersen for her help and advice regarding the literature search.

Contributors IL conducted literature search and initial screening for relevant studies. IL, JD, ABy and ABe conducted selection of studies, quality appraisal and synthesising data. IL prepared the manuscript. IL, JD, ABy and ABe contributed to the development of the manuscript and approved the final manuscript.

Funding The project was funded by The Research Council of Norway and is part of a larger project of Crosscare-old (project.nr. 256644/H10).

Competing interests None declared.

Patient consent for publication Not required.

Provenance and peer review Not commissioned; externally peer reviewed.

Data availability statement There are no data in this work.

Open access This is an open access article distributed in accordance with the Creative Commons Attribution Non Commercial (CC BY-NC 4.0) license, which permits others to distribute, remix, adapt, build upon this work non-commercially, and license their derivative works on different terms, provided the original work is properly cited, appropriate credit is given, any changes made indicated, and the use is non-commercial. See: http://creativecommons.org/licenses/by-nc/4.0/.

\section{REFERENCES}

1 King L, Harrington A, Linedale E, et al. A mixed methods thematic review: health-related decision-making by the older person. J Clin Nurs 2018;27:e1327-43.

2 Watts R, Gardner H, Pierson J. Factors that enhance or impede critical care nurses' discharge planning practices. Intensive Crit Care Nurs 2005;21:302-13.

3 Storm M, Siemsen IMD, Laugaland K, et al. Quality in transitional care of the elderly: key challenges and relevant improvement measures. Int J Integr Care 2014;14:e013.

4 Gautun H, Kristiansen F, Kjerstad E. Studie av konsekvenser for pleie- og omsorgstjenestene vedden registrerte og dokumenterte oppgaveendring innen den somatiske s. Mellom to senger? : eldre sykehuspasienter og det kommunale pleie- og omsorgstilbudet. Bergen: Stiftelsen for samfunns- og næringslivsforskning, 2001.

5 Galvin EC, Wills T, Coffey A. Readiness for hospital discharge: a concept analysis. J Adv Nurs 2017;73:2547-57.

6 Spehar AM, Campbell RR, Cherrie C, et al. Seamless care: safe patient transitions from hospital to home, 2005.

7 Deniger A, Troller P, Kennelty KA. Geriatric transitional care and readmissions review. J Nurse Pract 2015;11:248-52.

8 Suwan N, Panuthai S, Lasuka D, et al. Factors influencing readiness for hospital discharge among Thai older persons with chronic obstructive pulmonary disease. Pacific Rim International Journal of Nursing Research 2018;22:156-68.

9 Castro EM, Van Regenmortel T, Vanhaecht K, et al. Patient empowerment, patient participation and patient-centeredness in hospital care: a concept analysis based on a literature review. Patient Educ Couns 2016;99:1923-39.

10 Dyrstad DN, Testad I, Aase K, et al. A review of the literature on patient participation in transitions of the elderly. Cogn Technol Work 2015;17:15-34.

11 Naylor MD, Feldman PH, Keating S, et al. Translating research into practice: transitional care for older adults. J Eval Clin Pract 2009;15:1164-70.

12 Hall AM, Ferreira PH, Maher CG, et al. The influence of the therapistpatient relationship on treatment outcome in physical rehabilitation: a systematic review. Phys Ther 2010;90:1099-110.

13 Steihaug S, Johannessen A-K, Ådnanes M, et al. Challenges in achieving collaboration in clinical practice: the case of Norwegian health care. Int J Integr Care 2016;16.

14 Bragstad LK, Kirkevold M, Hofoss D, et al. Informal caregivers' participation when older adults in Norway are discharged from the hospital. Health Soc Care Community 2014;22:155-68.
15 Mold A. Patient groups and the construction of the patient-consumer in Britain: an historical overview. J Soc Policy 2010;39:505-21.

16 Longtin Y, Sax H, Leape LL, et al. Patient participation: current knowledge and applicability to patient safety. Mayo Clinic Proceedings 2010;85:53-62.

17 Sandelowski M, Barroso J. Handbook for syntesizing qualitative research. New York: Springer Publishing Company, 2007.

18 Sandelowski M, Barroso J, Voils Cl. Using qualitative metasummary to synthesize qualitative and quantitative descriptive findings. Res Nurs Health 2007;30:99-111.

19 Barnett-Page E, Thomas J. Methods for the synthesis of qualitative research: a critical review. BMC Med Res Methodol 2009;9:59.

20 Braun V, Clarke V. Using thematic analysis in psychology. Qual Res Psychol 2006;3:77-101.

21 Dixon-Woods M, Agarwal S, Jones D, et al. Synthesising qualitative and quantitative evidence: a review of possible methods. J Health Serv Res Policy 2005;10:45-53.

22 Holloway I, Todres L. The status of method: flexibility, consistency and coherence. Qualitative Research 2003;3:345-57.

23 Braun V, Clarke V. What can "thematic analysis" offer health and wellbeing researchers? Int J Qual Stud Health Well-being 2014;9:26152.

24 Lincoln YS, Guba EG, Pilotta JJ. Naturalistic inquiry. Beverly Hills, Calif: Sage, 1985: 9. 438-9.

25 Bryman A. Social research methods. 5th ed. Oxford University Press: Oxford, 2016.

26 Patton MQ. Qualitative research \& evaluation methods : integrating theory and practice. 4th ed. Los Angeles, Calif: Sage, 2015.

27 Swinkels A, Mitchell T. Delayed transfer from hospital to community settings: the older person's perspective. Health Soc Care Community 2009;17:45-53.

28 Gabrielsson-Järhult F, Nilsen P. On the threshold: older people's concerns about needs after discharge from hospital. Scand J Caring Sci 2016;30:135-44.

29 Ekdahl AW, Linderholm M, Hellström I, et al. 'Are decisions about discharge of elderly hospital patients mainly about freeing blocked beds?' A qualitative observational study. BMJ Open 2012;2:e002027.

30 Efraimsson E, Sandman P-O, Rasmussen BH. "They were talking about me"--elderly women's experiences of taking part in a discharge planning conference. Scand J Caring Sci 2006;20:68-78.

31 Wong C, Hogan DB. Care transitions: using narratives to assess continuity of care provided to older patients after hospital discharge. Canadian Geriatrics Journal 2016;19.

32 Dyrstad DN, Laugaland KA, Storm M. An observational study of older patients' participation in hospital admission and discharge - exploring patient and next of kin perspectives. J Clin Nurs 2015;24:1693-706.

33 Durocher E, Gibson BE, Rappolt S. Mediators of marginalisation in discharge planning with older adults. Ageing Soc 2017;37:1747-69.

34 Popejoy LL. Complexity of family caregiving and discharge planning. J Fam Nurs 2011;17:61-81.

35 Nyborg I, Danbolt LJ, Kirkevold M. User participation is a family matter: a multiple case study of the experiences of older, hospitalised people and their relatives. J Clin Nurs 2017;26:4353-63.

36 Efraimsson E, Sandman P-O, Hydén LC, et al. How to get one's voice heard: the problems of the discharge planning conference. $J$ Adv Nurs 2006;53:646-55.

37 Perry MAC, Hudson S, Ardis K. "If I didn't have anybody, what would I have done?": Experiences of older adults and their discharge home after lower limb orthopaedic surgery. J Rehabil Med 2011;43:916-22.

38 Durocher E, Gibson BE, Rappolt S. Rehabilitation as "destination triage": a critical examination of discharge planning. Disabil Rehabil 2017;39:1271-8.

39 Rydeman I, Törnkvist L. Getting prepared for life at home in the discharge process - from the perspective of the older persons and their relatives. Int J Older People Nurs 2010;5:254-64.

40 Laugaland K, Aase K, Waring J. Hospital discharge of the elderly--an observational case study of functions, variability and performanceshaping factors. BMC Health Serv Res 2014;14:365.

41 Knight DA, Thompson D, Mathie E, et al. 'Seamless care? Just a list would have helped!' Older people and their carer's experiences of support with medication on discharge home from hospital. Health Expect 2013;16:277-91.

42 McBride RC. An audit of current discharge planning arrangements and their effectiveness on elderly care wards and community nursing services together with aspects of client satisfaction. J Nurs Manag 1995;3:19-24.

43 Bull MJ. Patients' and professionals' perceptions of quality in discharge planning. J Nurs Care Qual 1994;8:47-61. 
44 Sixsmith J, Sixsmith A, Fänge AM, et al. Healthy ageing and home: the perspectives of very old people in five European countries. Soc Sci Med 2014;106:1-9.

45 Daatland SO, Høyland K. Boliggjøring AV eldreomsorgen? Oslo: Velferdsforskningsinstituttet NOVA, 2014.

46 Munkejord MC, Eggebø H, Schönfelder W. Hjemme best? Tidsskrift for omsorgsforskning 2018;4:16-26.

47 Perry TE. Moving as a gift: relocation in older adulthood. J Aging Stud 2014;31:1-9.

48 Ness TM, Hellzen O, Enmarker I. "Embracing the present and fearing the future": The meaning of being an oldest old woman in a rural area. Int J Qual Stud Health Well-being 2014;9:25217.

49 Harsløf I, Ulmestig R. Changing social risks and social policy responses in the Nordic welfare states. Basingstoke: Palgrave Macmillan, 2013

50 Berglund $\mathrm{H}$, Dunér A, Blomberg S, et al. Care planning at home: way to increase the influence of older people? 2012.

51 Durocher E, Kinsella EA, Ells C, et al. Contradictions in client-centred discharge planning: through the lens of relational autonomy. Scand $J$ Occup Ther 2015;22:293-301.

52 Elwyn G, Frosch DL, Kobrin S. Implementing shared decisionmaking: consider all the consequences. Implement Sci 2016;11.

53 Jansen J, Naganathan V, Carter SM, et al. Too much medicine in older people? Deprescribing through shared decision making. BMJ 2016;353:i2893.

54 van Vliet M, Huisman M, Deeg DJH. Decreasing Hospital length of stay: effects on daily functioning in older adults. J Am Geriatr Soc 2017;65:1214-21.

55 Groene O, Sunol R. Patient involvement in quality management: rationale and current status. J Health Organ Manag 2015;29:556-69.

56 Dent M, Pahor M. Patient involvement in Europe - a comparative framework. J Health Organ Manag 2015;29:546-55.

57 Askheim OP, Christensen K, FLUGE S, et al. User participation in the Norwegian welfare context: an analysis of policy discourses. J Soc Policy 2017;46:583-601.
58 Christensen K, Fluge S. Brukermedvirkning i norsk eldreomsorgspolitikk - Om utviklingen AV retorikken Om individuelt medansvar. Tidsskrift for velferdsforskning 2016;19:261-77.

59 Bull MJ, Roberts J. Components of a proper hospital discharge for elders. J Adv Nurs 2001;35:571-81.

60 Flink M, Öhlén G, Hansagi H, et al. Beliefs and experiences can influence patient participation in handover between primary and secondary care-a qualitative study of patient perspectives. BMJ Qual Saf 2012;21:i76-83.

61 Bradley S, Mott S. Adopting a patient-centred approach: an investigation into the introduction of bedside handover to three rural hospitals. J Clin Nurs 2014;23:1927-36.

62 Coulter A, Parsons S, Askham J, et al. Where are the patients in decision-making about their own care? 2008.

63 Slatyer S, Toye C, Popescu A, et al. Early re-presentation to hospital after discharge from an acute medical unit: perspectives of older patients, their family caregivers and health professionals. J Clin Nurs 2013;22:445-55.

64 Blaum CS, Rosen J, Naik AD, et al. Feasibility of implementing patient priorities care for older adults with multiple chronic conditions. J Am Geriatr Soc 2018;66:2009-16.

65 Vabø M. Organisering for velferd: hjemmetjenesten i en styringsideologisk brytningstid. Oslo: Norsk institutt for forskning om oppvekst, velferd og aldring, 2007.

66 Levinson W, Kao A, Kuby A, et al. Not all patients want to participate in decision making. J Gen Intern Med 2005;20:531-5.

67 Elwyn G, Frosch D, Thomson R, et al. Shared decision making: a model for clinical practice. J Gen Intern Med 2012;27:1361-7.

68 Paillaud E, Canoui-Poitrine F, Varnier G, et al. Preferences about information and decision-making among older patients with and without cancer. Age Ageing 2017;64:665-71.

69 Pearson M, Hunt H, Cooper C, et al. Providing effective and preferred care closer to home: a realist review of intermediate care. Health Soc Care Community 2015;23:577-93.

70 Lipsky M. Street-level bureaucracy: dilemmas of the individual in public services. 30th anniversary expanded ed. New York: Russel Sage Foundation, 2010. 